\title{
Herrschaftslegitimation in vorderorientalischen Reichen der Eisenzeit
}

\author{
Hrsg. v. Christoph Levin u. Reinhard Müller
}

Herrschaftslegitimation in vorderorientalischen Reichen der Eisenzeit

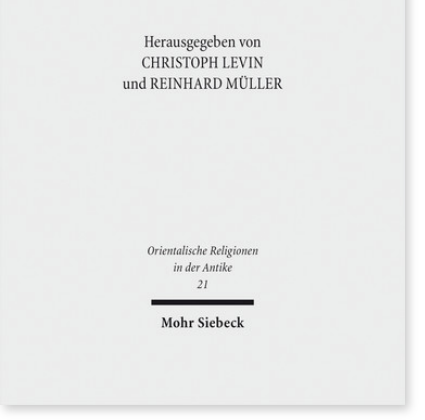

2017. XI, 315 Seiten. ORA 21

ISBN 978-3-16-155028-7

DOI 10.1628/978-3-16-155028-7

Book PDF 139,00

ISBN 978-3-16-154858-1

Leinen $139,00 €$
Der Sammelband behandelt Formen und Strategien von Herrschaftslegitimation, die in eisenzeitlichen Königtümern der Levante sowie in Mesopotamien und Ägypten ausgeprägt wurden. Anhand von ikonographischen, textlichen und archäologischen Zeugnissen werden die Grundmuster herausgearbeitet, mit denen in diesen Reichen königliche Herrschaft legitimiert wurde. Besondere Aufmerksamkeit gilt den kulturellen Wechselwirkungen, die zwischen den Regionen bestanden, sowie den Eigenheiten der einzelnen Königtümer. Schwerpunkte liegen auf Babylon und Assur, den phönizischen Königtümern, Kinalua/Tell Tayinat, den Inschriften von Bukān, Tell Fekheriye und Sfire, den Bildwerken von Balu'a, Yarih-'ezer und Askalon, den Königtümern Israel, Juda und Moab, ägyptischen Einflüssen auf die levantinischen Reiche sowie der Königsmotivik im Hohenlied.

Inhaltsübersicht

Joachim Friedrich Quack: Ägyptische Einflüsse auf nordwestsemitische Königspräsentationen? - Claus Ambos: Rituale der Herrschaftslegitimation babylonischer und assyrischer Könige - Karen Radner: Assur's »Second Temple Period«. The restoration of the cult of Aššur, c. 538 BC - Paolo Xella: Self-depiction and Legitimation: Aspects of Phoenician Royal IdeologyWilliam Morrow: Famine as the Curse of Kings: Royal Ideology in Old Aramaic Futility Curse Series - Bob Becking: A Voice from Across the Jordan: Royal Ideology as Implied in the Moabite Stela - Angelika Berlejung: Dimensionen der Herrschaftslegitimität: Ikonographische Aspekte königlicher Selbstdarstellung in den Kulturen der südlichen Levante der Eisenzeit anhand der Bildwerke von Balu'a, Yarih-'ezer und Askalon - Reinhard Müller: Herrschaftslegitimation im israelitischjudäischen Königtum. Eine Spurensuche im Alten Testament - Christoph Levin: Das Königsritual in Israel und Juda - Udo Rüterswörden: Das Königtum im Hohenlied - Timothy Harrison: Royal self-depiction and legitimation of authority in the Levantine monarchies of the Iron Age in light of newly excavated royal sculptures at Tell Tayinat

Christoph Levin Geboren 1950; 1998 bis zu seiner Emeritierung 2016 Professor an der Ludwig-Maximilians-Universität München; Mitglied der Akademie der Wissenschaften zu Göttingen und der Finnischen Akademie der Wissenschaften; 201013 Präsident der International Organization for the Study of the Old Testament (IOSOT).

Reinhard Müller Geboren 1972; 2004 Dr. theol. (Göttingen); 2008 Habilitation (München); Professor für Altes Testament an der Georg-August-Universität Göttingen.

https://orcid.org/0000-0002-2303-7688

Jetzt bestellen:

https://mohrsiebeck.com/buch/herrschaftslegitimation-in-vorderorientalischen-reichen-der-eisenzeit-9783161550287?

no_cache=1

order@mohrsiebeck.com

Telefon: +49 (0)7071-923-17

Telefax: $+49(0) 7071-51104$ 